\title{
St. Petersburger Ophtalmologische Gesellschaft
}

\section{Sitzung am 80. November 1906}

Demonstrationeu:

Blessig: Beiderseitiger Kryptophtalmus eieatrieeus. Die Ver- $\Lambda$ vachsung der Lidspalten hat nach einer schweren Erkraukung im 8. Lebens-jahre stattgefunden. Am rechten Auge soil eine Operation versueht werden, mit allerdings sehr geringen Aussichten auf Erfolg.

Botwinik: Nach ausgedehnter Verbrennung durch Säure Plastik des oberen und unt $\beta F \beta n$ Lides reehts dureh Hautlappen naeh Tiepseh. Urn die Augenbrauen zu markieren ist die Haut tätowiert worden. Stiehelung und Touche.

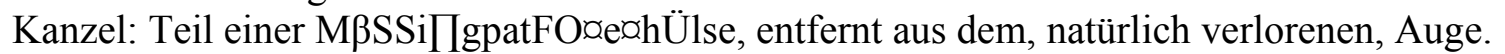
Kardo-Sisoew demonstriert einen Knaben von 14 Jahren. Auf traeh'omatöser Basis amyloide Degeneration der Bindehaut beider Augen. Der mikroskopische Befund hat die klinische Diagnose bestätigt.

Wainstein bemerkt zu dieser Vorstelluno, dass von 6 Tumoren in der Sammlung des Augenhospitals die klinische Diagnose „Amyloidtumor bei Trachom” durch das Mikroskop hinterher nicht bestätigt wurde - in drei Fallen.

Wainstein stellt einen Patienten vor, bei welchem In der Extraktions narbe eingeheilte KapselF $\beta$ Ste zu sehen sind. $\Lambda$ 7or vier Jahren extrahierí worden. Der Krankenbogen gibt an, dass die Kammer lange Zeit - 2 Wochen - sich nicht herstellte. Eine sorgfältige Toilette der Wunde dürfte diese $Z \alpha \Gamma$ älle vei'ineiden helfen.

Schiedlowsky: Uebep die Wirkung des Adonidin auf das Auge.

Von einer 2proz. Lösung im LauГe von 5 Minuten 2 Tropfen. Nach 25 Minuten voile Anästhesie, welcbe dann 3-4 Stunden anhält. Gleich nach der Appli-kation starke stetig ansteigende allgemeine Reizerscheinungen am Auge, und an Nebenwirkungen Kop $\Gamma$ schmerzen, Nebelsehen, Farbenringe, bitterer Ge-schmack im Munde. Die Reizerscheinungen halten etwa 1 Stunde lang an und gehen dann zurück. Um unter Adonidin zu operieren, mussten die Reizerscheinungen erst abgewartet werden. Die sehr starke Hyperãmie kann zum ïeil durch $x \backslash d r e n a l i n$ bekämpft werden. Braucht man eine lproz. Lüsung so ergibt sich dasselbe Bild und der gleiche Verlauf, nur alles entsprechend kürzer andauernd. Eine Lösung von ]/2 pCt. genügt schon nicht mehr um ausreichende Anästhesie zu erzielen.

Akkornmodation und Tension wird durch Adonidin nicht beeinflusst, es bewirkt aber cine geringe Pupillenverengerung. Eine schãtzbare Eigenschaft ist die schmerzstillende Wirkung, was an Glaukom-kranken und in Fallen von Iritis und Iridocyklitis erwiesen wurde. Ein damit behandelter Glaukomkranker wird vorgestellt. Um Schmerzen zu beseitigen genügen ]/4 bis lproz. LösungeD. Naclidem das Adonidin die Schmerzen beseitigt hat, wird, natürlich je nach der indikation, Pilocarpin, Eserin, Atropin oder Ilyoscyn gegeben. Mit dem Kokain vermag es nicht zu konkurrieren a!s Anaestheticum.

192

Buchanzeige. 
Wainstein: EiП Fall VOП ÛPbitaleyste. Anatomische makro- und mikroskopische Besclireibung, sowie Demonstration von Schnitten.

Sitzung am 14. Dezember 1906.

Nikanorow spricht übӨP Isophysostigmin. An Kaninchen wirkt eine lproz. Lösung schneller und energischer als eine lproz. Eserinlösung. Eine lproz. Salicyl - Isophysostigminlösung ist sehr viel haltbarer als eine lproz. Salicyl-Eserinlösung. Die allmählicL · eíntretende Rötung der Lösung ist weniger stark. Schimmelpilze, welche in Eserinlösungen leicht auftreten, wurden in der Isophysostigminlösung nie beobachtet. Die 1 proz. Lösung des Prãparates ist bakteriocider wirkend als lproz. Eserinlösung. Subkutan 15 Tropfen der lproz. Lösung tödten ein Kaninchen in 35 Minuten.

In das menschliche Auge wurde eine 1/10proz. Lösung geträufelt und gut vertragen. Drei Tropfen '/10proz. setzen den Augendruck deutlich herab, und diese Herabsetzung dauert länger an als bei lproz. Eserinlösung. Isophisostigmin verursachte in keinem Falle Schmerzen wie es ja bei Ge-brauch des Eserin nicht selten der Fall ist. Ein Akkommodationsspasmus tritt schnell ein und halt längere Zeit an. Hypermetropiegrade bis z $\alpha-\mathrm{j}-4 \mathrm{D}$ wurden stets in Myopie übergeführt unter dem Einfluss des Isophy-sostigmins. Auch nach 2 Monate andauerndem Gebrauche wurden schlechte Nebenwirkungen, wie Konjunktivitis, nicht beobachtet. Eine lproz. Atropinlösung überwindet die Wirkung der VioP1"02- Isophisostigminlösung bereits nach einer halben Stunde. Zur Zeit ist es dreimal so teuer als Eserin.

Kubly demonstriert und spricht über den praktisehen WOrt der Perfagläser, Orthoskopisehe-, Enlxanthos-, Franklin-, Unibifo-Glâsep. Die letztgenannten Gläser, ein englisches Fabrikat, sind sehr zu empfehlen, aber sie sind noch zu teuer. Gläser gelber Fãrbung empfiehlt Blessig den Arbeitern der Elektrotechnik, zu Schneebrillen sowie Aphakischen.

Germann.

Buchanzeige,

Lađdolt, Mare., La surface de section des plaies faites en vue de

Textraction de la cataracte et de l'iridectomie. Paris 1905.

G. Steinheil, Editeur.

Die bisherigen Betrachtungen unserer Lanzen- und Messerschnitte haben, sagt Landolt, nur selten darauf Rücksicht genommen, dass die gewölbte Schale, welche wir durchschneiden, eine gewisse Dicke hat. So untersuchte man bisher kaum mal die entstehenden Schnittflächen und achtete selten auf die Differenzen, welche zwischen dem äusseren, sichtbaren und dem inneren, das Auge erst wirklich eröffnenden (dem „nutzbaren”) Schnitt obwalten können. Diese Verhältnisse stellt nun Landolt durch seine 130 Seiten umfassende Monographie in jeder Beziehung klar.

A. Als Grundlage seiner Betrachtungen nimmt er eine Hornhautscheibe von $1 \mathrm{~mm}$ gleichmässiger Dicke an. Durch die Einfalzung der Cornea in die Sklera entsteht eine vordere und eine hintere Hornhautgrenze. Zwei Ebenen welche senkrecht zur sagittalen $\Lambda$ ugenachse durch je einen Punkt dieser Grenzen gelegt werden geben die vordere und die hintere Basalebene der Cornea. Die hintere ist 3,5 $\mathrm{mm}$ vom Hornhautpol entfernt tangiert genau die Vorderfläche der Linse und schneidet die Aussenfläche der Sklera seitlich etwa $1,25-1,5 \mathrm{~mm}$ oben und unten $2.5 \mathrm{~mm}$ jenseits des Limbus. Dadurch dass die vordere Grenzlinie oben und unten weiter nach vorn greift als seitlich 
sind zwei vordere Basalebenen denkbar: eine oberûächliche', 